\title{
Educação Inclusiva para Surdos: Reflexões de Intérpretes de Libras e Professores de Física dos Municípios de Nova Mutum e Tangará da Serra - MT
}

\section{Inclusive Education for the Deaf: Reflections of Brazilian Sign Language Interpreters and Physics Teachers in the Municipalities of Nova Mutum and Tangará da Serra - MT}

\author{
Marciele Keyla Heidmann*a; Sumaya Ferreira Guedes ${ }^{\mathrm{a}}$
}

${ }^{a}$ Universidade do Estado de Mato Grosso, Programa de Pós-Graduação Stricto Sensu em Ensino de Ciências e Matemática MT, Brasil.

*E-mail: marciele.keyla@unemat.br

\begin{abstract}
Resumo
A Política Nacional de Educação Especial dispõe sobre formas de incluir a pessoa surda no Ensino Regular. Este estudo tem por objetivo analisar a conceituação do termo inclusão na visão de professores, que ministram o componente curricular de Física e Tradutores Intérpretes de Língua de Sinais (TILS), e verificar se a formação acadêmica, entre outras, tem influência na inter-relação com o estudante surdo em sala de aula comum. Para tanto, foram realizadas entrevistas semiestruturadas, de abordagem qualitativa, com tratamento baseado na análise de conteúdo, por meio de três categorias. Os resultados apontam para o despreparo dos professores de Física, perante a ausência de algum tipo de formação direcionada para Libras, seja essa inicial, ou contínua, dificultando o acesso às informações pertinentes, como a conceituação do termo inclusão, inferindo na interação direta com o estudante surdo e na promoção da Educação Inclusiva. Portanto, reflexões acerca da obrigatoriedade do componente curricular de Libras, em conformidade com o Decreto 5.626/2005, pelas Instituições de Ensino Superior, que ofertam cursos de Licenciaturas se faz necessário, assim como a formação continuada de intérpretes de Libras e professores de Física da Educação Básica, em prol a um ensino de qualidade diante da inclusão de estudantes surdos.
\end{abstract}

Palavras-chave: Língua Brasileira de Sinais. Educação Especial. Educação Inclusiva.

\begin{abstract}
The National Special Education Policy provides for ways to include the deaf in regular education. This study aims to analyze the conceptualization of the term inclusion in the view of teachers who teach the curricular component of Physics and Brazilian Sign Language Interpreters (TILS) and to verify whether academic training, among others, influences the inter-relationship with the deaf student in a common classroom. To this end, semi-structured interviews were conducted, with a qualitative approach, with treatment based on content analysis, through three categories. The results point to the unpreparedness of physics teachers, in the absence of some type of training directed to Brazilian Sign Language, be it initial or continuous, making it difficult to access relevant information, such as the concept of the term inclusion, inferring in the direct interaction with the deaf student and promoting Inclusive Education. Therefore, reflections on the compulsory nature of the Brazilian Sign Language component, in accordance with Decree 5.626 / 2005, by Higher Education institutions, which offer undergraduate courses, are necessary, as well as the continued training of Brazilian Sign Language interpreters and teachers of Basic education physics, in favor of quality teaching in view of the deaf students inclusion.
\end{abstract}

Keywords: Brazilian Sign Language. Special Education. Inclusive Education.

\section{Introdução}

A educação para surdos tem se destacado no cenário educacional brasileiro. Conforme dados do Instituto Nacional de Estudos e Pesquisas Educacionais Anísio Teixeira (INEP), os números do Censo Escolar, de 2019, registraram 20.087 estudantes surdos e 36.314 com deficiência auditiva matriculados na Educação Básica no Brasil (INEP, 2019). Os dados refletem a presença de estudantes surdos e deficientes auditivos, em salas de aula, acompanhados pela atuação de um profissional Tradutor e Intérprete da Língua Sinais (TILS), no intuito de viabilizar o acesso a uma escola inclusiva.

$\mathrm{O}$ trabalho em equipe diante das práticas pedagógicas a serem elaboradas deve ser repensado em conjunto dos dois profissionais (professor e TILS) para que consigam promover acessibilidade aos estudantes surdos em qualquer Instituição de Ensino (DORZIAT; ARAÚJO, 2012). Tal pensamento corrobora com algumas inquietações sobre os desafios e potencialidades gerados na parceria entre professores, que ministram aulas de Física e TILS na perspectiva de uma Educação Inclusiva para surdos.

Lacerda e Santos (2013, p.215) evidenciam que "A proximidade do professor amplia as possibilidades de um trabalho colaborativo, existindo abertura para discussões sobre possíveis adaptações, troca de informações e de ideias para um melhor trabalho em sala de aula". Considera-se que essa relação colaborativa entre professores e TILS tende a promover a integração do estudante surdo e do Deficiente Auditivo (DA) no ensino regular e contribuir durante os processos de ensino e aprendizagem em sala de aula comum.

Costa (2014) destaca a pertinência da formação continuada 
de TILS e professores, da mesma forma que a prática pedagógica voltada para a inclusão de estudantes surdos e dispõe reflexões acerca desta temática. Tendo em vista que "os professores não são e nem recebem treinamentos para serem capacitados a ministrar aulas para alunos surdos. A realidade é que os alunos com (DA) acabam ficando frustrados por não compreenderem o que está sendo repassado (SILVA et al. 2016, p.9).

Oliveira (2016) descreve a relevância que a Língua Brasileira de Sinais (Libras) representa durante os processos de ensino e aprendizagem diante das relações entre professor (mediador), intérprete (intermediador) e estudante surdo (receptor). E Ayoub (2020) evidencia que a comunicação entre professor e demais integrantes do ambiente escolar fica restrita, comparada com a relação existente entre o TILS e o estudante surdo. Desse modo, é necessário compreender como atuam a formação inicial e continuada de professores de Física e TILS perante as ações e relações pedagógicas, mediante a Educação Inclusiva para estudantes surdos?

Segundo Heidmann et al. (2020), reflexões acerca da temática no ensino de Física para surdos com abordagem em Libras são pertinentes, tendo em vista a quantidade de produções acadêmicas entre 2014 a 2019, que foi verificada. Sendo assim, investigar sobre a oferta do componente curricular de Libras, na formação inicial docente ou em cursos de formação continuada para professores de Física e TILS, se faz necessário, pois influencia na relação de qualidade entre professor/intérprete/estudante surdo e na compreensão de uma Educação Inclusiva para surdos.

Diante do exposto, foram convidados a participar da pesquisa, professores de Física e TILS, que atuam na rede pública de ensino, localizadas no interior do Estado de Mato Grosso (Tangará da Serra e Nova Mutum). Para a coleta de dados, foram realizadas três reuniões de modo coletivo, via Google Meet, tendo como instrumento para recolha dos dados, entrevistas semiestruturadas. As discussões dos dados foram organizadas em três categorias, com base na Análise de Conteúdo de Bardin (2016). As reflexões direcionam para de professores de Física e TILS, que tiveram algum tipo de contato com a Libras, durante sua formação inicial e/ou continuada, e de que forma esse contato interferiu na atuação de práticas pedagógicas diante da Educação Inclusiva de surdos.

Portanto, este estudo teve como objetivo analisar a conceituação do termo inclusão na visão de professores que ministram o componente curricular de Física e TILS e verificar se a formação acadêmica, bem como cursos de capacitação e/ ou formação continuada direcionados a Libras, influenciam na inter-relação com o estudante surdo em sala de aula comum.

\section{Material e Métodos}

Em função da necessidade de isolamento social ocasionada pela Pandemia mundial da doença de coronavírus (COVID-19), que teve início em 2019, foi necessário adequar o modo operandi da pesquisa, trocando a modalidade presencial, pelo acesso remoto, do qual se escolhe como instrumento de coleta de dados a entrevista, por meio da oferta de três reuniões coletivas (grupo focal), realizadas com o recurso tecnológico Google Meet, gravadas após consentimento dos participantes.

A pesquisa dispõe da aprovação do Comitê de Ética para realização com número do parecer 3.636.574. Aos participantes foi informado sobre os objetivos e métodos adotados na pesquisa, em que os mesmos, voluntariamente, aceitaram fazer parte, e assinaram Termo de Consentimento Livre e Esclarecido (TCLE). Nesse sentido, foram convidados professores que ministram o componente curricular de Física e TILS, que atuam na rede pública de ensino nos municípios de Nova Mutum e Tangará da Serra, localizados no interior do Estado de Mato Grosso.

Desse modo, foram adotadas abordagens com princípios de grupo focal como técnica para a coleta de dados, em que cada reunião é considerada "espaço de discussão e de troca de experiências em torno de determinada temática" (BACKES et al, 2011, p. 2). As reuniões aconteceram em dois grupos separados, um com os professores de Física e outro com os intérpretes de Libras, mediadas por um roteiro de entrevistas semiestruturadas para ambos os grupos. As reuniões foram realizadas em três dias consecutivos, com duração média de 60 a 90 minutos cada uma, a fim de manter a fidedignidade quanto à coleta de dados para sua análise e discussão.

Durante o processo de coleta de dados foram lançados questionamentos, que abrangiam a temática Educação Inclusiva para surdos, entre os quais estavam a definição do termo inclusão, formação inicial e continuada, a inter-relação entre estes profissionais e o estudante surdo, direcionado ao contato com a Libras. De modo geral, os participantes ouvem as opiniões, uns dos outros antes de formar as suas próprias respostas e, constantemente, mudam de posição, ou fundamentam melhor sua opinião inicial, quando envolvidos na discussão em grupo (BACKES et al., 2011).

Após a coleta de dados, a análise foi moldada, por meio das relações entre as partes (professores de Física e TILS), que foram reveladas. Desse modo, busca-se identificar alguns termos estruturantes que fundamentam a investigação qualitativa, que devem ser conhecidos e estar contidos em uma análise qualitativa: os substantivos experiência, vivência, senso comum e ação social, e os verbos compreender e interpretar (MINAYO, 2012). Assim, o processo interpretativo dos dados coletados teve seu desfecho pela preparação e reunião dos dados, juntamente com a avaliação de sua qualidade e, por fim, na elaboração de categoria de análises.

$\mathrm{Na}$ sequência, aconteceu o tratamento dos resultados, com a transcrição das falas dos participantes, tabulação, interpretação, adaptação e adequação conforme os dados apontados por meio da indução analítica (roteiro de entrevistas) para se investigarem as causas (variáveis inferidas) a partir dos 
efeitos (variáveis de inferência ou indicadores, referências) (BARDIN, 2016).

Durante a análise e intepretação das entrevistas, buscase compreender as características, estruturas ou modelos que estão por trás dos fragmentos de mensagens, passando para a interpretação de conceitos e proposições como referência geral. Os conceitos derivam da cultura estudada (Física em Libras) e da linguagem dos informantes (depoimentos dos entrevistados), a fim de comparar ações entre si e verificar a existência de convergências ou divergências neste processo.

Na procura da inter-relação dos trabalhos de professores que ministram a aulas de Física e a atuação do TILS, em prol o ensino de Física, diante do cenário da Educação Inclusiva para surdos, busca-se respaldar nos seguintes trabalhos: Dorziat e Araújo (2012), Pereira e Rizzatti (2013), Dos Santos e Lacerda (2015), Rautenberg (2017), Da Conceição e Pereira (2019), entre outros autores, que tratam de trabalhos pertinentes à área da Educação Inclusiva dos surdos para fundamentar este estudo.

\section{Resultados e Discussão}

Primeiramente, para exploração do material foram ouvidas as falas dos sujeitos da pesquisa, assemelhando-se à fase de leitura flutuante, buscando se familiarizar com as respostas dadas durante a realização das entrevistas, e a partir de então foram atribuídas algumas categorias correlacionadas ao objetivo desta pesquisa. Posteriormente, foi realizada a transcrição na íntegra das falas, sendo selecionados fragmentos das entrevistas de acordo com a relevância de cada categorização estabelecida, separada e numerada para determinar critérios de análises.

Durante as várias e cuidadosas escutas e leituras das transcrições das entrevistas foram criadas três categorias de análise: 1 - Conceituação do termo "Inclusão", 2 - Formação/ Capacitação em Libras e, 3 - Relações entre professor/ intérprete/estudante surdo. As categorias foram utilizadas para o tratamento dos resultados, com o enfoque nos apontamentos dos professores de Física e TILS acerca da Educação Inclusiva para surdos nas salas de aulas comuns. Dessa maneira, para melhor compreensão e identificação das discussões dos dados apresentados, os fragmentos dos relatos dos participantes da pesquisa, estão em itálico e os professores de Física (P) foram codificados como P1 até P5 e os intérpretes de Libras (I) de I1 a I6.

\subsection{Categoria 1 - Conceituação do termo "Inclusão"}

A categoria sobre a conceituação do termo Inclusão se destinou a compreender o que os professores, que ministram aulas de Física e TILS, entendem por esse termo, tanto no âmbito escolar, como fora desse, procurando identificar e coletar informações sobre como se posicionam perante a perspectiva da Educação inclusiva para surdos.

Diante dos relatos coletados, observa-se que a compreensão e a conceituação do termo "inclusão" para professores de Física diferem dos TILS, pois professores buscam exemplos como caminhos, experiências vividas em sala para conceituar inclusão e os intérpretes, em sua maioria, são diretos e objetivos descrevendo de fato a conceituação.

Para conceituar inclusão foram apontadas por P1, quesitos como empatia e metodologias diferenciadas, para que todos os tipos de estudantes tenham acesso ao conteúdo da mesma forma, buscando alternativas que oportunize aquele estudante com dificuldade ter o ensino de modo igualitário.

[...] uma palavra que tá sendo usada bastante é empatia né, ultimamente, é você tentar ter essa empatia né, por todos os tipos de alunos, e você tentar é passar o conteúdo, é da mesma maneira para todos né, e pra aqueles que possuem algum tipo de dificuldade é buscar alternativas para conseguir atingir aquele aluno, com metodologias diferenciadas para que todos possam ali ter a mesma oportunidade de ensino. (P1, entrevista realizada em 29/10/2020).

Nessa linha de raciocínio, o participante P2 relata que é necessário criar, inventar, buscar por recursos didáticos apropriados para estimular as potencialidades e superar as limitações durante os processos de ensino e aprendizagem dos estudantes (Pessoas com Deficiência - PcD), deixando evidente esses quesitos como sendo a problemática da inclusão em sala de aula.

[...] eu acho que é problemática dentro de sala de aula para o ensino né, para igualar a metodologia é criar, inventar, buscar recursos didáticos pra aquela determinada deficiência daquele aluno perceber que se a gente não adequar o recurso didático para deficiência daquele aluno $\mathrm{PcD}$, porque se a gente não adequar os recursos didáticos pra aquela deficiência que ele possui, o ensino-aprendizagem vai ter igual, vamos dizer assim, a zero pra todas as partes né, a gente tem que aumentar as potencialidades daquele aluno dentro da sala de aula, e eu acho que a gente é, inclui eles trazendo recursos didáticos apropriados para a limitação e a deficiência que ele possui. (P2, entrevista realizada em 29/10/2020).

Na visão de P3, o importante não é dar uma aula igual para todos, mas sim adotar metodologias específicas, para que sejam respeitadas as diferenças deste estudante com necessidades, fazendo com que ele seja igual na diferença e assim aconteça a inclusão e não a exclusão.

[...] sobre inclusão e exclusão, é... Eu acredito né, não adianta dar uma aula igual pra todos, eu acredito, que o aluno que tem a determinada necessidade, tem que ser respeitada a diferença dele, ele tem que ser igual na diferença, então, acredito que precise fazer algumas metodologias específicas pra atender esse aluno é basicamente isso. (P3, entrevista realizada em 29/10/2020).

De acordo com Dorziat e Araújo (2012), os contextos escolares se mantêm excludentes, em função da concepção oriunda do termo inclusão, que confunde e gera conflitos diante dos papéis e atitudes entre professores e TILS, ocasionado pelo descompasso entre as políticas construídas a partir de ideias simplistas e ilusórias de inclusão e formações inadequadas. Nesse aspecto, o P4 destacou a falta de infraestrutura na escola pública para uma inclusão efetiva, evidenciando os 
desafios da ausência de formação e de pessoas especializadas na modalidade da Educação Especial para atuar, bem como o despreparo dos profissionais para receber e atender, de forma igualitária, estes estudantes para que ocorra de fato a inclusão na escola pública.

[...] é ter uma pessoa especializada para atender ele, então, são desafios que a gente enfrenta, não tem a formação e os alunos né, não só os surdos né, todas as entendo e a gente observa que infelizmente o espaço da escola pública ela não tem a inclusão que a gente gostaria que tivesse que eu acho que todos tenham acesso a mesma, ao mesmo atendimento né, então para que a gente possa fazer isso, a gente vai ter que trabalhar bastante para chegar até essa inclusão de fato. (P4, entrevista realizada em 29/10/2020).

Ainda, o P5 descreve que sua percepção em relação à inclusão sofreu influências pelo contato que teve em sua faculdade com o componente curricular de Libras, ocasionando reflexões sobre a conscientização e responsabilidade, que todos deveriam ter perante a ausência de pessoas surdas em diferentes espaços públicos, inclusive nas salas de aula.

[...] foi uma disciplina que mudou minha visão em relação a inclusão né, [...], a vida inteira eu não tive contato com os surdos né, nem vi, aula nem assim, não tive contato, então na faculdade quando eu vi a disciplina, foi que me veio o questionamento: aonde estavam essas pessoas enquanto eu estudava? [...] as pessoas estavam nas suas casas porque não tinha oportunidade nas salas de aula né, é, tipo é muito é muito doloroso você sabe disso né, eu acho que a gente se, a gente se sente até um pouco culpado, responsável né, porque a gente não cobra isso, a gente não tem consciência disso [...] depois faz com que você começa a ver né, as pessoas surdas, a impressão depois, [...] parece que a partir do momento que você conhece a Libras, você vê as pessoas se comunicando né, então assim eu achava super interessante, eu sou muito curiosa e ficava olhando assim né, observando, mas eu acho lindo lindo [...]. (P5, entrevista realizada em 29/10/2020).

Os relatos destes profissionais de ensino condizem com as percepções das autoras Dorziat e Araújo (2012), em que as políticas de inclusão precisam ser repensadas de uma forma globalizada, envolvendo projetos culturais e sociais, de modo que a inclusão não seja reduzida apenas à acessibilidade dos $\mathrm{PcD}$ às escolas regulares de ensino e nem à condição de medidas paliativas em cumprimento da legislação, em prol de uma efetiva mudança social.

Desse modo, pode-se perceber que a Educação inclusiva é composta de um modelo educacional com fundamenta nos direitos humanos, sem distinção de deficiências, em que todos os estudantes se encontram no mesmo estabelecimento de ensino e compartilham estímulos de aprendizagem em salas de aulas comuns (MANTOAN, 2015).

$\mathrm{Na}$ visão de quatro dos intérpretes de Libras educacional entrevistados se identificam nos excertos a presença de características que evidenciam o acesso e permanência, o direito de ir e vir, a igualdade para todos, para que se efetive uma inclusão de qualidade nos diversos âmbitos da sociedade, conforme assegura a Constituição Federal (CF) de 1988 e a Lei de Diretrizes e Bases da Educação Nacional (LDB), Lei $n^{\circ} 9394 / 96$.
[...] eu defino ela como direito de acesso e igualdade a todos né, [...] eu vejo como um direito de acesso e permanência né, a todos. (I1, entrevista realizada em 29/10/2020)

[...] incluir todos não só uma deficiência né, ah... só o surdo, ou só o cego, mas de uma forma geral incluir é... nesse meio, na sociedade de uma forma que eles se sintam à vontade, livres [...]. (I2, entrevista realizada em 29/10/2020)

[...] tudo tudo deve ser acessível né, porque que para eu que eu que escuto, eu consigo ter acesso a tantas coisas, mas o surdo não pode ter esse acesso, então pra mim inclusão é isso, é abrir uma porta para eles, para que eles possam ter as mesmas condições e acessibilidades e direitos e as escolhas que nós temos, porque a gente pode ver que para nós os ditos normais nós temos " $n$ " escolhas né, e para eles às vezes essas escolhas são limitadas, então é... inclusão é isso, é que eles possam escolher viver assim como eu [...]. (I5, entrevista realizada em 29/10/2020)

[...] inclusão pra mim, no meu ponto de vista assim, eh é uma, como uma escola, né! A escola hoje, ela inclui os alunos com deficiência, certo? Então, esse incluir, sim, é uma, como diz, foi uma coisa tão importante para esses alunos com necessidades especiais, devido que antes, né, como todos, é de conhecimento de muitos, né, eles ficariam numa escola diferenciada, de uma escola dito anormais né, com os alunos dito normais, como antes eles ficavam no APAE, certo? Aí, hoje eles ficam numa escola dita normais, certo? Então, inclusão pra mim hoje é... foi uma coisa muito importante né, que os alunos puderam abrir mais, ampliar mais, um ponto de vista deles, como eles têm direito de ir e vir, certo? Eles tem, assim, a a consciência que eles podem fazer igual a uma pessoa que não tem uma deficiência, entendeu? Então, essa inclusão deles foi, nossa, foram fantástica. [...] as escolas foram jogando para os mercados de trabalho, graças a Deus, que hoje tem tipo uma lei, né! Que ele tem que ter um deficiente né, tem que ter algo no mercado de trabalho, foi muito importante, isso pra mim eu considero uma inclusão. (I6, entrevista realizada em 29/10/2020)

Dois dos TILS entrevistados também retratam a relevância quanto ao indivíduo surdo querer estar nesse meio e saber aproveitar as oportunidades que lhe são dadas. Esse querer pode estar ligado à diferentes fatores, como afirma Mantoan (2015), envolve mudanças no contexto educacional como um todo, não direcionado apenas aos estudantes PcD ou aqueles que possuem algum tipo de dificuldades de aprender, mas todos os estudantes, para que o sucesso alcance a educação em geral.

Carmo et al. (2018) evidenciou que o método bilíngue, neste processo da aceitação e superação de fatores, que dificultam o processo da Educação Inclusiva, pode por meio da identidade natural trazer benefícios e integrar o visual e o gestual, contribuindo assim, em seu desenvolvimento escolar, quanto como sujeito da sociedade.

[...] é uma via de mão dupla, aonde também esse excluído tem que ser, sentir, tem que querer ser incluído, então não não faz parte só da sociedade ouvinte porque nós estamos falando em relação ao surdo não, é só para não faz parte só ouvinte mas também faz parte do surdo, esse surdo também tem que querer ser incluído. Então, acho que a palavra e a ação, querer, impulsiona qualquer ação, enquanto nós não quisermos, enquanto nós não tivermos empecilhos em relação a isso, tanto ouvintes quanto surdos a inclusão não irá acontecer, acho que é um caminho longo e acredito na inclusão [...]. (I3, entrevista realizada em 29/10/2020) 
[...] quando nós pensamos em inclusão, a gente pensa sempre no lado, de nosso lado né, do que que nós podemos fazer para incluir, essa questão do outro, também importante [...] porque as oportunidades elas devem ser dadas né, mas o outro tem que saber aceitar essas oportunidades de forma positiva [...] é uma luta grande é uma luta extensa, longo prazo né, já é uma luta longo prazo e que os resultados virão sim, se nós continuarmos com esse intuito de valorização, das diferenças, tentando também buscar esse outro lado, o interesse do próprio surdo, em valorizar essa essa essa inclusão dele [...].(I4, entrevista realizada em 29/10/2020)

De Oliveira e Beneti (2015) explicitaram, em seu estudo sobre a importância do trabalho cooperativo entre os diversos profissionais, que fazem parte do ambiente escolar, sendo esses especializados ou não, o trabalho a ser desenvolvido diante das diferenças demanda modificações no currículo, adaptações e implementação de programas de formação continuada, para que o ambiente seja propício não só em sala de aula, mas em todos os espaços de acesso comum aos estudantes. Dessa forma, fica claro que na escola inclusiva:

[...] não há aulas específicas para surdos, mas sim que uma aula bem elaborada, com recursos visuais, beneficia a todos os alunos, sejam surdos ou ouvintes. Muitos dos recursos visuais que foram utilizados para ensinar os alunos surdos foram muito bem aproveitados para se fazer entender conteúdos aos alunos ouvintes (AMPESSAN; GUIMARÃES; LUCHI, 2013, p. 33).

De acordo com Carmo et al. (2018), a Educação Inclusiva propicia a interação entre $\mathrm{PcD}$ e as que não possuem deficiências, a partir do tratamento igualitário, no qual a mediação proporcione a esses estudantes o desenvolvimento, favorecendo suas potencialidades. Desse modo, a oferta das mesmas condições para comunicação e interação com o Mundo, sendo oferecidas tanto para surdos, como para ouvintes, oportunizam também a integração na sociedade.

\subsection{Categoria 2 - Formação/Capacitação em Libras}

Esta categoria se destinou a investigar o grau de contato com Libras, seja esse por meio da formação inicial e continuada ou capacitações (cursinhos), durante a graduação e/ou posteriormente a essas. Busca-se evidenciar a importância da Libras quanto componente curricular durante a formação acadêmica, capacitações e formações continuadas, tanto para professores regentes, quanto para TILS, em prol do sucesso da inclusão do estudante surdo. E ainda, procura-se saber sobre o preparo dos professores que ministram aulas de Física para receber e atender estes estudantes surdos.

A Libras, como componente curricular, nos cursos de licenciatura em todo Brasil, foi estabelecida desde o ano de 2005 pela implantação do artigo terceiro do Decreto Federal $n^{\circ} 5.626 / 2005$. Dos cinco professores entrevistados, apenas dois tiveram contato com Libras durante a Graduação, mesmo que a maioria tenha ingressado e concluído sua formação acadêmica durante o período vigente da legislação, os cursos não ofertaram o componente curricular de Libras, ou se ofertaram, foi de modo optativo, não obrigatório, conforme demanda o decreto.

Nesse aspecto, as autoras Da Conceição e Pereira (2019) descreveram, em seu estudo, sobre a importância da formação e capacitação de professores ouvintes para o ensino e aprendizagem de estudantes surdos e a as percas ocasionas pela ausência da Libras, durante seu processo educacional. Assim, o envolvimento do professor é considerado como ferramenta principal de subsídio aos estudantes surdos, durante a troca de informações entre ambos, por meio da comunicação no ambiente escolar (DA CONCEIÇÃO; PEREIRA, 2019).

Apesar de não terem contato com Libras durante a graduação, dois dos professores entrevistados fizeram um curso de Libras, em formação continuada fornecida pela escola na qual trabalhavam, e apesar disso, não se sentem preparados para atender um estudante surdo em suas aulas, mas descrevem ter disposição para aprender, como pode ser observado na fala do professor P1.

[...] não era obrigatório ainda a Libras né, e o contato que eu tive, é... além de fazer foi na formação continuada, [...] em um dos anos eu participei do curso, foi o único contato que eu tive referente a língua de sinais, a linguagem de sinais.[...] preparada não estou, mas assim eu tenho muita disposição em querer aprender, [...]. (P1, entrevista realizada em 29/10/2020)

Em contrapartida, dois dos entrevistados nunca tiveram contato algum com a Língua de Sinais (LS), seja na graduação ou pela oferta de cursos durante a formação continuada das escolas. Dessa forma, cursos de licenciatura, de modo geral, praticamente não apresentam em sua grade curricular a oferta de componentes curriculares na área da Educação Especial, que possibilite aos futuros professores trabalhar com estudantes com algum tipo de deficiência, e claramente os estudantes sofrem com isso nas aulas, em função da falta de preparo deste profissional (DA CONCEIÇÃO; PEREIRA, 2019).

Nos relatos de P3 e P4 pode ser identificado que ambos ainda não tiveram formação alguma em Libras. No entanto, os participantes P1 e P2 destacam terem tido contato com a Libras durante formação continuada, fornecida pela instituição de ensino, na qual trabalhavam. Esses relatos reforçam a afirmação de Kassar (2014) e Sígolo e Kumada (2017), de que a formação inicial e/ou continuada do educador deve possibilitar uma capacitação crescente para o fazer pedagógico inclusivo envolto das atribuições dos agentes envolvidos nesse processo (professores e intérpretes).

É importante destacar que, mesmo sem formação, todos os entrevistados afirmaram ter vontade de aprender Libras para realizar um atendimento de qualidade ao estudante surdo, [...] não somente dar o conteúdo específico, mas pra mante assim uma comunicação com o aluno, que eu acho que seria algo importante para ele [...] (P1, entrevista realizada em 29/10/2020). Nesse sentido, Góes (2020) reforça que experiências de interlocução entre professor e estudante surdo se detém aos sistemas combinados de fala mais sinais, por isso, de modo geral, aquele que se propõe a utilizar sinais, não 
faz uso afetivo da LS.

Rautenberg (2017) em seu estudo retratou a relevância da integração professores e TILS juntamente com a comunidade surda, para haver contribuição na criação de sinais que representem conceitos científicos. Por isso, termos científicos utilizados durante os processos de ensino e aprendizagem de Física são considerados difíceis para sinalização, pela maioria dos professores, estudantes surdos e intérpretes, conforme relata $\mathrm{P} 2$ :

[...]é muito difícil a gente trabalhar no em relação ao ensinoaprendizagem, porque a gente não sabe como vai passar pro aluno os termos científicos, talvez ele não conheça, porque Libras, a gente pensa que faz um sinal uma coisa, mas para eles significa outra coisa, então assim, no termo científico fica difícil a gente trabalhar o específico né, dentro do ensino, e outra, como eu também não tenho contato diário com alguém com deficiência, eu ficaria na verdade, eu fico perdida quando vou falar de alguma coisa específica, a gente entende coisas básicas, é coisas bem básica mesmo, mas se partir para o específico, o termo científico, aí já não consigo nem se comunicar, eu acho que até o intérprete, tem coisas que, ficam meio perdido, como explicar aquilo para o aluno, dentro do histórico da linguagem deles [...]. (P2, entrevista realizada em 29/10/2020)

Com isso, pode-se compreender que não basta apenas o professor saber Libras para que o ensino e a aprendizagem aconteça, precisa também este profissional se munir de métodos que se adequem aos conceitos abordados, conforme descrevem Da Conceição e Pereira (2019):

Além dos profissionais capacitados em Libras, é necessário que haja uma organização didática para o ensino desses alunos. É preciso trabalhar por meio de imagens visuais que referencie todo tipo de assunto a ser trabalhado no ambiente escolar (DA CONCEIÇÃO; PEREIRA, 2019, p. 151).

Para que o ensino e aprendizagem aconteça de modo efetivo na Educação Inclusiva para surdos, sendo preciso ter nas escolas a infraestrutura e artefatos necessários para amparar os professores durante esse processo, como descreve P4:

[...] se você tem um aluno surdo você vai ter que buscar a forma de atender ele com qualidade né, seja é... fazer um curso, mesmo que seja por conta, porque infelizmente o que acontece na na rede pública, é isso, é você buscar por conta própria [...] (P4, entrevista realizada em 29/10/2020).

Diante do exposto, pode-se perceber que a falta de um primeiro contato durante a formação acadêmica, com o componente curricular de Libras e a ausência de capacitações e formações continuadas nesta área, juntamente com o baixo suporte técnico das instituições, demonstram serem agentes propulsores, na problemática da Educação inclusiva para surdos. Essas características levam ao sentimento de impotência perante a situação da inclusão do estudante surdo, conforme descreve P3:

[...] eu teria bastante dificuldade, é... no caso, teria uma intérprete que teoricamente faria essa transposição de conteúdo né, $[\ldots]$ então eu acredito que eu, eu teria muita dificuldade em trabalhar com o aluno com deficiência auditiva. (P3, entrevista realizada em 29/10/2020).
A presença do TIL aparece como uma segurança para o professor, que ministra aulas de Física, diante da dificuldade admitida em se trabalhar com estudante que seja deficiente auditivo. Portanto, nesse espaço chamado de sala de aula, do qual se precisa da mediação, o papel do intérprete é fundamental para manutenção da comunicação entre ambos (CABRAL; CÓRDULA, 2017).

Pereira e Rizzatti (2013) retrataram, em seu trabalho, sobre cursos de Pedagogia ou licenciaturas em Educação Especial, como sendo formações exclusivas para professores atuarem com estudantes surdos. O componente curricular de Libras assegurado pelo Decreto 5.626/2005 demonstra estar presente de fato nestes cursos, pois dos seis TILS participantes da pesquisa, quatro deles tiveram Libras durante sua graduação:

[...] já atuo na área né da educação inclusiva algum tempo, quando eu fiz Pedagogia já existia uma disciplina de Libras, porém bastante superficial né, nada de te dar influência nem nem o básico o suficiente né, para você atuar numa sala, porém depois esse conhecimento que você vai buscar, fora sua formação vai tentar esse conhecimento extra né. (I1, entrevista realizada em 29/10/2020).

[...] eu tive o conhecimento da Libras quando eu fiz Pedagogia, a minha turma foi uma das primeiras a ter essa disciplina, $[\ldots]$ eu fiz cursos, [...]. (I2, entrevista realizada em 29/10/2020).

[...] eu tive contato com a Libras durante e após a conclusão da minha faculdade de Pedagogia, [...] meu contato maior foi justamente com a surda [...] eu realmente vi que, eu era, que eu gostava e me apaixonei também pela Libras e aí desde então continuei [...] a interpretar, a atuar, [...]. (I4, entrevista realizada em 29/10/2020).

[...] eu conheci a Libras é..., antes de me formar em Pedagogia também né... antes de tudo, [...] devido a minha família né, basicamente minha família toda, quase toda surdas, então a gente cresceu nesse mundo surdo né, [...] então, esse conhecimento eu tive antes né, nesse mundo inclusão, antes de me formar, [...] eu já comecei a estudar, indo para Cuiabá, começando a estudar já Libras aí então, foi assim, formalizei né, [...]. (I6, entrevista realizada em 29/10/2020).

Os demais intérpretes entrevistados não tiveram contato com Libras na graduação. No caso de I3, sua formação acadêmica é anterior à data de obrigatoriedade regida pela lei, destacou ainda, ter aprendido Libras interagindo e socializando com a comunidade surda da qual faz parte, e apenas após dominar esta língua buscou cursos para sua qualificação.

[...] eu sou professora e intérprete de Libras, atuo há mais de 20 anos nessa área, quando eu me formei em Pedagogia não existia nem se quer, se falava sobre educação especial, era a parte, era separado, [...] meu crescimento profissional e pessoal, foi o contato com o surdo adulto usuário da Língua de Sinais, [...] me apresentaram a língua, me ensinaram, me desafiaram e contribuíram com o meu crescimento profissional, [...] eu participei de cursos de Libras somente depois que dominei-a, [...]. (I3, entrevista realizada em 29/10/2020).

Do modo análogo, I5 teve contato com a Libras na infância, por intermédio de sua mãe intérprete e por intermédio dos surdos adultos, atuando na informalidade, somente após adulta formalizou sua profissão com a certificação. Dos intérpretes participantes é o único sem formação acadêmica em Pedagogia, pois cursa Psicologia, curso do qual Libras é 
componente curricular de caráter optativo, segundo consta no capítulo II do artigo $3^{\circ}$ do decreto 5.626/2005:

[...] eu sou só intérprete de Libras, ainda não sou professora [...] eu tive contato com a Libras desde que eu nasci, através da minha mãe e através de todos esses surdos adultos aí, foram eles que me ensinaram quando eu era bem pequena, ... me tornei intérprete só depois com 17, 18 anos que eu fui correr atrás de certificação, nesse período da minha infância até os meus 18 anos foi só na informalidade como intérprete, [...]. (I5, entrevista realizada em 29/10/2020)

Quanto à inter-relação de professores e intérpretes, Dos Santos e Lacerda (2015, p. 514) argumentam que deve haver uma "parceria com o professor, e também com o aluno, sem que tais relações demarquem uma postura favorável a um ou outro". Nessa ótica, quatro dos intérpretes de Libras consideram como fundamental a parceria dentro de sala de aula, pontuando que o professor precisa compreender o verdadeiro trabalho deste profissional intérprete, conhecer as adaptações curriculares e, assim, entender e propiciar ao estudante surdo um ensino de qualidade.

Para os intérpretes entrevistados, os professores precisam estar acessíveis e despertar o interesse em se sensibilizar, pois para eles $[. .$.$] sobre o professor, falta olhar um pouquinho né,$ para a situação [...] (I1, entrevista realizada em 29/10/2020), tendo em vista, que muitos só buscam a formação na modalidade de Educação Especial por obrigatoriedade, sem ter o entendimento da importância, que significa para o aprendizado do estudante surdo.

[...] os professores várias vezes alguns eram acessíveis, outros não, [...] a formação por exemplo, às vezes ela vem obrigatória entendeu? Aí, aquele professor ele ele acha um saco fazer essa formação e aí engole goela abaixo essa formação, aí é tudo um saco, poder adaptar é tudo um saco entendeu então assim eu não sei, tinha que entrar no psicológico desse professor de alguma forma, porque tentar enfiar goela abaixo não dá certo. (I5, entrevista realizada em 29/10/2020)

O despreparo de professores, que ministram aulas de Física, vai além de ensinar apenas termos científicos, específicos em Libras e adequação de material, como já citado anteriormente, pois envolve fatores que demonstram a discrepância na alusão de inclusão deste surdo em salas de aula comuns. A realidade percebida diante desses sujeitos se associa com falta de preparo dos professores e intérpretes; falta de comunicação entre professores e estudantes surdos; invenção de sinais para termos específicos (BARBOSA; ROSA, 2017).

Nesse sentido, dentro da sala de aula se necessita expor de maneira coesa os papéis de cada um destes profissionais. "O professor é responsável pelo ensino, por proporcionar o conhecimento científico ao aluno" (DOS SANTOS; LACERDA, 2015, p. 514). Enquanto o profissional TILS "Sua função é de viabilizar a comunicação entre surdos e ouvintes, atuando na fronteira entre os sentidos da língua oral (português) e da língua de sinais em um processo ativo dinâmico e dialético" (LACERDA; SANTOS, 2013, p. 206). Portanto, o preparo do professor quanto às suas ações e relações pedagógicas para receber e atender estudantes surdos precisam ser revistas, conforme retratam as falas de I3 e I5:

[...] nosso professor ele ainda não não não não sabe utilizar uma metodologia adequada onde possa atingir todos não só em relação ao surdo mas, qualquer outro aluno né, [...] depende do professor, mas eu acho que a grande maioria ainda deixa um pouco a desejar [...] (I3, entrevista realizada em 29/10/2020).

[...] é difícil assim para os professores conseguirem pensar no deficiente né, normalmente pensam na maioria, [...] (I5, entrevista realizada em 29/10/2020).

A falta de um olhar para a compreensão da adaptação [...] pra ele adaptar a atividade, ele tem que compreender essa adaptação [...] (I1, entrevista realizada em 29/10/2020). [...] não há adaptação de material (I5, entrevista realizada em 29/10/2020), juntamente com a indicação acerca de [...] uma questão de parceria mesmo, acho que falta talvez um pouco talvez humildade, tanto do nosso lado, quanto do lado do professor, [...] (I4, entrevista realizada em 29/10/2020) e essa parceria o intérprete vai ajudar ele a entender, para que ele possa produzir materiais que venham de fato ajudar o desenvolvimento desse aluno surdo [...] (I2, entrevista realizada em 29/10/2020).

Relatos que demonstram a essência de uma parceria diante do desenvolvimento do indivíduo surdo e a necessidade de uma unificação, concretizando que "é preciso que professor e intérprete caminhem lado a lado, afinal, para que ambos possam atuar da melhor forma possível, é preciso cooperação e reciprocidade" (DOS SANTOS; LACERDA, 2015, p. 515).

\subsection{Categoria 3 - Relacionamento entre professor/ intérprete/estudante surdo}

Nesta categoria, busca-se perceber a existência de algum tipo de desconforto com a presença do estudante surdo ou do TILS, em sala de aula, por parte do professor de Física. E ainda, procura-se demonstrar como os professores que ministram aulas de Física lidam com a inserção do estudante surdo, se eles procuram algum tipo de aproximação, se ocorre o entrosamento (contato direto) entre o estudante surdo e o professor.

Diante do exposto por professores e TILS, para que a inclusão de fato do estudante surdo se efetive existe um longo caminho a ser trilhado. A presença do TILS, em sala de aula, em função do desconhecimento desta função, ocasiona desconforto, medo e insegurança em professores na visão destes profissionais. Enquanto professores de Física alegam como fundamental a presença do TILS em sala de aula, tendo em vista que os mesmos não se sentem aptos para atender este público. No entanto, demonstraram determinação e força de vontade para aprender a trabalhar com eles, diante da ausência da oferta de capacitações e/ou formações continuadas.

O Decreto Federal no 5.626 (BRASIL, 2005) dispõe que é direito do aluno com surdez possuir um intérprete que o acompanhe no ambiente escolar. No entanto, identifica-se nos fragmentos relatados pelos professores que ministram aulas de Física, o uso de terminologias inapropriadas como: surdos 
e mudos e professora de Libra (P1, entrevista realizada em $01 / 11 / 2020$ ), fazer gestos e abri bem minha boca articular no vocabulário (P2, entrevista realizada em 01/11/2020), eu não sei o que esses gestos significa $(\mathrm{P} 3$, entrevista realizada em 01/11/2020), pessoa especializada e acompanhante (P4, entrevista realizada em 01/11/2020), acompanhante (P5, entrevista realizada em 01/11/2020).

Esses excertos evidenciam o desconhecimento tanto da Libras estabelecida como língua oficial das pessoas surdas, pela Lei $n^{\circ}$ 10.436/2002 (BRASIL, 2002), quanto sobre quem é o profissional intérprete de Libras educacional, determinado por Brasil (2002, p. 11) “pessoa que traduz e interpreta a língua de sinais para a língua falada e vice e versa em quaisquer modalidades que se apresentar (oral ou escrita)".

De modo geral, essa ausência de conhecimento por parte dos professores acerca do profissional intérprete são detectadas e descritas por eles em alguns termos: me ignora, ter medo e se sente ameaçado (I1, entrevista realizada em $01 / 11 / 2020$ ), como se eu tivesse fiscalizando o trabalho deles (I2, entrevista realizada em 01/11/2020), questão de intimidar e fiscalizando o trabalho (I4, entrevista realizada em 01/11/2020), fingiram que a gente não existia e tem medo (I5, entrevista realizada em 01/11/2020), não tem aquela total confiança (I6, entrevista realizada em 01/11/2020). Por isso, é importante que professores vençam as barreiras e desafios, conforme descrevem Lacerda e Santos (2013):

Se o professor não assumir práticas que favoreçam a atuação do ILS, consequentemente a compreensão do aluno surdo ficará comprometida. Para desenvolver práticas acadêmicas acessíveis, é necessário, antes de qualquer adaptação curricular, que haja parceria entre professor e ILS. (LACERDA; SANTOS, 2013, p.196).

Dos Santos e Lacerda (2015) retratam que essa parceria entre professor da sala de aula regente e o TILS como sendo vital. Nesse quesito, a percepção dos professores de Física diverge da visão dos TILS, e demonstraram em suas falas a inter-relação com uma pessoa especializada em Libras como sendo necessária sinto até falta do intérprete, parceria, eu sinto segurança, eu me sinto segura tendo ali o intérprete do lado (P1, entrevista realizada em 01/11/2020), Intérprete é essencial (P2, entrevista realizada em 01/11/2020), Eu acho essencial a presença do intérprete $(\mathrm{P} 3$, entrevista realizada em 01/11/2020), [...] a gente não tem pessoas com formação, para atender o aluno e, infelizmente, o Estado também não tava concedendo [...] (P4, entrevista realizada em 01/11/2020), o intérprete é fundamental (P5, entrevista realizada em 01/11/2020).

No entanto, algumas divergências nas falas de dois professores de Física foram detectadas em relação à questão do professor se direcionar ao estudante surdo, comparadas pelas descritas pelos TILS. O P1, expõe sua busca em aprender sinais, mesmo de forma simplificada, sob orientação do TILS para tentar contato, aproximando-se e direcionandose ao estudante surdo, para que o mesmo se sinta valorizado, porém deixa claro que essas ações não significam que haja inclusão de fato. O P2 coloca que gosta da presença do TILS em sala de aula e também, tem como fundamental essa parceria entre professor e TILS, evidenciando que deve haver conscientização dos professores em relação ao surdo pertencer à esta sociedade.

Quanto ao contato com o estudante surdo, o P2, diz ter conhecimento de algumas "coisinhas" em Libras para se comunicar, mas quando se tratam de termos científicos, precisa do apoio da intérprete e que às vezes nem sequer o intérprete consegue transmitir como cita "de um lado a linguagem científica que é dotada de simbologia própria e é compartilhada por uma comunidade científica, de outro, o intérprete de LIBRAS que muitas das vezes não a domina" (DE OLIVEIRA; BENETI, 2015, p. 619).

[...]a intérprete é essencial, precisa, tá ali e nós professores também temos que ter ciência que nós estamos falando com crianças com alunos que vivem a sociedade, que eles entendem também a leitura labial por isso é importante você virar pra eles e determinada situação quando for falar com eles falar olhando para eles de frente pra eles, [...] eu gosto de intérprete, acho que todo mundo gosta, [...] assim, eu sei falar poucas coisas, coisinhas básicas do dia a dia... Oi! tudo bem? e tal, [...] dentro do ensino e outra, como eu também não tenho contato diário com alguém com deficiência, eu ficaria na verdade eu fico perdida quando vou falar de alguma coisa específica, [...]. (P2, entrevista realizada em 01/11/2020)

Enquanto P3, P4 e P5 ainda não tiveram a presença do estudante surdo, em sala de aula, acreditam que a presença do TILS é essencial para a comunicação. P3 relatou que tentou contato com um surdo fora do ambiente escolar por meio de um aplicativo, “[...] sim já tive, contato e foi até um aluno desse meu amigo, tipo nós se encontramos num bar, aí esse aluno dele tava lá, ele sentou com a gente, aí a gente tentou até usar o aplicativo pra se comunicar com ele [...]" (P3, entrevista realizada em 01/11/2020). Nonnenmacher (2012, p.18) conceitua "[...] aplicativos são pequenos softwares instalados em sistemas operacionais de smartphones e tablets, com possibilidade de acessar conteúdos on-line e off-line". No entanto, não entendia nada dos "gestos" que o mesmo fazia, [...] eu não estava entendendo, o que ele estava tentando me transmitir, eu pedia: escreva, que ele sabia escrever né, escreva que eu, pra mim entender, daí não, ele voltava e repetia os mesmos gestos [...] (P3, entrevista realizada em 01/11/2020).

P4 disse que esse ano seria o primeiro ano que teria contato com um surdo e que em função da Pandemia não ocorreu, ainda descreveu sobre o despreparo da escola e da equipe, a falta de formação e "pessoa especializada" para receber este estudante surdo. Contudo, P5 apesar de nunca ter tido a experiência com estudante surdo incluso em sala de aula, relatou que teve a presença de uma "acompanhante" e que a relação era tranquila, e ainda, reafirmou ter seu único contato com a Libras durante a faculdade.

Em contrapartida, na visão da maioria dos intérpretes de Libras, os professores se direcionam a eles e não ao estudante surdo, conforme identificado nos vestígios dos depoimentos: 
[...] eu falo pode perguntar para ele, eu intermedio, aqui, eu faço a tradução, eu interpreto pra ele, mas pode perguntar para ele, e aí eu percebo que as pessoas imaginam, que por a pessoa ser surda ela é intelectualmente incapaz, também, porque não é só porque ela não está ouvindo a impressão que dá é que eles entendem que o surdo também não pensa. Então você tem que fazer a comunicação e pensar pelo surdo, então muitas vezes o que eu percebo é isso, né! [...] (I1, entrevista realizada em 01/11/2020).

[...] E com relação a eles perguntarem diretamente pra gente, sempre, eu acho que a maioria. Maioria que, principalmente quando é o primeiro contato né, também mas eles sempre se direcionam para os intérpretes, sempre... A gente fala assim, não... pode perguntar pra ele, que eu vou fazer só a tradução, mas mesmo assim, eles ainda continuam perguntando diretamente pra a gente. E eu sempre falo, não, pergunta pra ele, que eu faço a tradução e eu acho que a maioria é assim, né!?[...] (I2, entrevista realizada em 01/11/2020).

[...] o professor se direciona ao intérprete e não ao surdo, mas [...] também tem muito a postura do surdo, porque você tem surdo que ele já vem com uma postura, [...], Então, eu acho que isso tem da questão do próprio surdo né, dessa autonomia do surdo vim, e pega, e dele mesmo [...] ir na frente, daí ele vai se direciona, através do olhar como se eu não estivesse ali, como se nenhum intérprete tivesse ali ele vai se direciona, pega e fala, e a gente dá a voz, e responde, entende, é isso que eu quero dizer... [...] (I3, entrevista realizada em 01/11/2020). [...] se direcionar a mim e não a aluna, [...] que eu estava lá para interpretar intermediar [...] pra que ela se direcionasse mais a aluna do que a mim (I4, entrevista realizada em $01 / 11 / 2020)$.

[...] mas não só dentro do ambiente de trabalho, mas em outros lugares também onde eu estava com o surdo é sempre falam: Fala pra ele... Fala pra ela que eu queria isso, fala pra ele, nunca fala diretamente com o surdo [...] (I5, entrevista realizada em 01/11/2020).

[...] eu não entendo muito bem, as perspectivas de um professor né, mas tem uns não né, [...] se solta mesmo né, questiona pergunta como que deve ser feito, busca, tem aquele que busca, mesmo pra uma melhora para o aluno né, [...] (I6, entrevista realizada em 01/11/2020).

E ainda, pode-se verificar a angústia e desabafo quanto à indignação sobre a colocação dos professores regentes perante o desconhecimento de suas funções e da capacidade e potencialidades do indivíduo surdo, na fala às vezes, até acham [...] de que surdo não pensa né, e querem que a gente pense por ele, responda por ele e opine por ele." (I5, entrevista realizada em 01/11/2020). E I1 complementa:

[...] porque ele não conhece a função do intérprete, a utilização desse acesso que ele faz da comunicação em Libras. E aí, prejudica o trabalho deles e o nosso, e aí prejudica nosso aluno também. [...] compreende que o surdo também é intelectualmente incapaz (I1, entrevista realizada em 01/11/2020).

Como já visto anteriormente, TILS concordam quanto ao posicionamento dos professores acerca do contato e direcionamento ao estudante surdo, dizendo que a maioria deles se direciona ao intérprete e não ao estudante, conforme pontuam Borges e Nogueira (2013, p. 4) “direcionam-se erroneamente ao profissional ouvinte e não diretamente ao surdo",

Dorziat e Araújo (2012) constataram, em seu estudo, que professores delegam aos TILS muitas funções que eram docentes, causando confusões e conflitos nos papéis pedagógicos, perante a inclusão de estudantes surdos, em decorrência de ideias distorcidas geradas por meio de políticas que foram construídas de forma simplistas e utópicas.

Nesse sentido, identificam-se trechos nas falas dos TILS, que demonstraram a existência de momentos, dos quais os intérpretes buscam além do interpretar/traduzir/intermediar para que haja uma aprendizagem significativa inclusiva para surdos“[...] porque uma das funções do intérprete é essa, não tá lá na ética não tá na normativa, mas daí a gente tem que se posicionar como educador [...]" (I3, entrevista realizada em 01/11/2020) e [...] buscar o tempo para o experimentar e sempre pensando com esse olhar, o olhar de educador também, não só de intérprete [...] (I4, entrevista realizada em 01/11/2020). Diante dos excertos, que diz sobre a função do intérprete ir além da ética e das normativas, tendo que por vezes, se posicionar como educador, "Esse conflito existente sobre a própria atuação revela a urgência de esclarecimentos acerca de suas funções e um trabalho de formação que favoreça a construção do papel profissional a desempenhar" (KOTAKI; LACERDA, 2014, p. 212).

\section{Conclusão}

A inclusão de surdos nas salas de aula comum exige permanentes mudanças pedagógicas acerca de uma Educação Inclusiva para surdos, permeada por dificuldades que vão além da existência de um TILS apto a traduzir/intermediar/ interpretar fluentemente a Língua Portuguesa para Libras e vice-versa. Observa-se uma pseudo-inclusão diante das falas dos professores que ministram aulas de Física na cidade de Tangará da Serra/MT e Nova Mutum/MT, que delimitam gestos, escrita, mímicas como forma de se comunicar com o estudante surdo, bem como pontuam imagens e desenhos como sendo material adaptado. Esse despreparo, dito por eles, apresenta uma visão deturpada do real sentido da inclusão.

Diante dos dados coletados se pode perceber que quatro dos professores participantes da pesquisa não tiveram contato algum com o componente curricular de Libras na grade curricular dos cursos de Licenciatura. Desse modo, a formação inicial do professor de Física pode direcionar caminhos, que orientem na atuação destes profissionais de ensino, não só na conceituação do termo "inclusão", mas na compreensão da surdez, bem como da deficiência auditiva. A fim de alcançar o contato direto com o estudante surdo, produzindo materiais adaptáveis que explorem suas capacidades e potencialidades, diante das especificidades.

As análises deste estudo indicaram a inter-relação entre professores de Física e intérpretes de Libras participantes como de fundamental importância, não só nos processos de ensino e aprendizagem, mas também na interação e socialização deste estudante surdo. Tendo em vista, que a maioria destes professores não obtiveram formação alguma, os TILS podem contribuir, já que os mesmos detêm dessa especialização, em prol da promoção desse público. 


\section{Referências}

AMPESSAN, J.P.; GUIMARÃES, J.S.P.; LUCHI, M. Intérpretes educacionais de Libras: orientações para a prática profissional. Secretaria de Estado da Educação. Fundação Catarinense de Educação Especial. Florianópolis: DIOESC, 2013.

AYOUB, R.A.J. Professor, intérprete e aluno surdo: uma relação além da comunicação nas aulas de Educação Física. São Carlos: Universidade Federal de São Carlos, 2020.

BACKES, D.S et al. Grupo focal como técnica de coleta e análise de dados em pesquisas qualitativas. Mundo Saúde, v.35, n.4, p.438-442, 2011. doi: https://doi.org/10.15343/01047809.2011354438442 .

BARBOSA, H.A.G.; ROSA, K. As pessoas surdas no ensino de ciências: uma revisão bibliográfica. In: SIMPÓSIO NACIONAL DE ENSINO DE FÍSICA, 22, São Carlos, SP, 2017. Anais... São Paulo: Sociedade Brasileira de Física, 2017.

BARDIN, L. Análise de Conteúdo. São Paulo: Edições 70, 2016.

BORGES, F.A.; NOGUEIRA, C.M.I. A comunicação nas aulas de matemática intermediadas por intérpretes de Libras. In: ENCONTRO NACIONAL DE EDUCAÇÃO MATEMÁTICA. 2013. Curitiba. Disponível em: <http://sbem.iuri0094. hospedagemdesites.ws/anais/XIENEM/pdf/1186_1028_ID.pdf > Acesso em: 8 jan. 2021

BRASIL. Decreto $n^{\circ}$ 5.626, de 22 de dezembro de 2005. Regulamenta a Lei ${ }^{\circ} 10.436$, de 24 de abril de 2002, que dispõe sobre a Língua Brasileira de Sinais - Libras, e o art. 18 da Lei $\mathrm{n}^{\circ} 10.098$, de 19 de dezembro de 2000. Disponível em: <http:// www.planalto.gov.br/ccivil_03/_ato2004-2006/2005/decreto/ d5626.htm>. Acesso em 3 fev. $20 \overline{2} 1$.

CABRAL, R.M; CÓRDULA, E.B.L. Os desafios no processo de alfabetização de surdos. Rev. Educ. Pública, v.17, n.5, 2017. doi: 10.18264/REP.

CARMO, K.A. Educação inclusiva com surdos: estratégias e metodologias mediadoras para a aprendizagem de conceitos químicos. Manaus: Universidade Federal do Amazonas, 2018.

COSTA, M.A.C. Relação pedagógica professor, intérprete de lingua brasileira de sinais e o aluno surdo do curso de Pedagogia da UERN. Mossoró: Universidade do Estado do Rio Grande do Norte, 2014.

DA CONCEIÇÃO SANTOS, S.M.; PEREIRA, D. Libras e sua importância na formação de professores na educação de surdos. Rev. Encantar-Educ., Cultura Soc., v.1, n.2, p.139-158, 2019. doi: http://dx.doi.org/10.5935/encantar.

DE OLIVEIRA, W.D; BENITE, A.M.C. Estudos sobre a relação entre o intérprete de LIBRAS e o professor: implicações para o ensino de ciências. Rev. Bras. Pesq. Educ. Ciênc., v.15, n.3, p.597-626, 2015.

DORZIAT, A.; ARAUUJO, J.R. O intérprete de língua de sinais no contexto da educação inclusiva: o pronunciado e o executado: Rev. Bras. Educ. Esp., v.18, n.3, p.391-410, 2012. doi: 10.1590/ S1413-65382012000300004.
DOS SANTOS, L.F; DE LACERDA, CB.F. Atuação do intérprete educacional: parceria com professores e autoria. Cad. Trad., n.2, p.505-533, 2015. doi: https://doi.org/10.5007/21757968.2015v35nesp2p505.

GÓES, M.C.R. Linguagem, surdez e educação. São Paulo: Autores Associados, 2020.

HEIDMANN, M.K. et al. Estudos científicos de aplicativos móveis que abordem conceitos da disciplina de Física em Libras. Res. Soc. Develop., v.9, n.11, p.19, 2020. doi: http:// dx.doi.org/10.33448/rsd-v9i11.10009

INEP - Instituto Nacional de Estudos e Pesquisas Educacionais Anísio Teixeira. Censo Escolar, 2019. Disponível em: <https:// www.gov.br/inep/pt-br/areas-de-atuacao/pesquisas-estatisticas-eindicadores/censo-escolar/resultados> . Acesso em: 16 jan. 2021.

KASSAR, M.C.M. A formação de professores para a educação inclusiva e os possíveis impactos na escolarização de alunos com deficiências. Cad. Cedes, v.34, n.93, p.207-224, 2014. doi: https://doi.org/10.1590/S0101-32622014000200005.

LACERDA, C.B.F.; SANTOS, L.F. Tenho um aluno surdo, $e$ agora? Introdução à Libras e Educação de surdos. São Carlos: EDUFSCar, 2013.

MANTOAN, M.T.E. Inclusão escolar: o que é? Por quê? Como fazer? São Paulo: Summus, 2015.

MINAYO, M.C.S. Análise qualitativa: teoria, passos e fidedignidade. Ciênc. Saúde Coletiva, v.17, p.621-626, 2012. doi: https://doi.org/10.1590/S1413-81232012000300007

NONNENMACHER, R.F. Estudo do comportamento do consumidor de aplicativos móveis. Porto Alegre: UFRGS, 2012.

OLIVEIRA, A.P. et al. Sobre a ação mediada: intervenções pedagógicas no ensino de ciências para surdos em sala bilíngue. Goiânia: Universidade Federal de Goiás, 2016.

PEREIRA, G.A.; RIZZATTI, I.M. A educação inclusiva segundo os graduandos do curso de Licenciatura em Física, Matemática e Química da Universidade Estadual de Roraima. In: encontro nacional de pesquisa em educação em ciências. 2013. Águas de Lindóia: Brasil, 2013.

RAUTENBERG, E. As dificuldades no ensino de Física para alunos surdos. Florianópolis: Universidade Federal de Santa Catarina, 2017.

SÍGOLO, C.; KUMADA, K.M.O. Tradutor e intérprete da língua brasileira de sinais: caracterização do perfil solicitado em processos seletivos no estado de São Paulo. Rev. Ensino, Educ. Ciênc. Hum., v.18, n.4, p.445-450, 2017. doi: https://doi. org/10.17921/2447-8733.2017v18n4p445-450.

SILVA, C.D.B. et al. Ensino de línguas para alunos surdos em escolas do Pará e Sergipe. In: CONGRESSO BRASILEIRO DE EDUCAÇÃO ESPECIAL, 2016. Disponível em: <https:// proceedings.science/cbee/cbee7/papers/o-ensino-de-linguaspara-alunos-surdos-em-escolas-do-para-e-sergipe $>$. Acesso em: 19 jan. 2021. 